\title{
Managing Resources and Relations in Higher Education Institutions: A Framework for Understanding Performance Improvement
}

\author{
Sophia Shi-Huei Ho ${ }^{1}$ \\ University of Taipei
}

\author{
Michael Yao-Ping Peng ${ }^{2}$ \\ Hsuan Chuang University
}

\begin{abstract}
Changes in social systems demonstrate that various structural disadvantages have jointly led to increasing competition among higher education institutions (HEIs) in many countries, especially Taiwan. Institutional administrators must recognize the need to understand how to improve performance and consistently outperform other institutions. Building on two theoretical frameworks that link antecedents and institutional performance, this study examines the relationships among institutional resources, social capital, and performance within Taiwan's HEIs and the mediating role of institutional resources. By using structural equation modeling (SEM), we tested the multi-group model in three diverse HEI sizes: large, medium, and small. The results showed that each higher education institution, as a function of its history and past success, had different slack resources available, and these resource combinations were shown to be a relevant factor in explaining inter-higher-education-institution variance in each outcome. Considering HEI sizes, even small HEIs can enhance their performance through consolidating existing internal social capital and strengthening external social capital.
\end{abstract}

Keywords

Higher education • Institutional performance $\bullet$ Institutional resources $\bullet$ Social capital $\bullet$ Structural equation modeling

1 Graduate School of Educational Administration and Evaluation, University of Taipei, Taipei Taiwan. Email: shihuei@utaipei.edu.tw

2 Correspondence to: Michael Yao-Ping Peng, Postdoctoral Research Fellow, Michael Yao-Ping Peng, Institutional Research Center, Hsuan Chuang University, Hsinchu 30092, Taiwan. Email: s91370001@mail2000.com.tw

Citation: Ho, S. S., \& Peng, Y. P. M. (2016). Managing resources and relations in higher education institutions: a framework for understanding performance improvement. Educational Sciences: Theory \& Practice, 16, $279-300$. http://dx.doi.org/10.12738/estp.2016.1.0185 
Higher education institutions (HEIs) have recently been approaching saturation in Taiwan in terms of the intensity of their development. Their educational pattern has been transformed from education of the elite to education of the masses (Taylor, Webber, \& Jacobs, 2013). Moreover, Taiwan's birth rate has plummeted from 2.06 in 1984 to only 1.07 in 2013 (Ministry of Interior, 2014). As a result, increasing competition among HEIs demonstrates that these various disadvantages have jointly led to an oversupply of HEIs. If HEIs' competing against one another is currently acceptable, then it is necessary to consider the following questions: "Why do some HEIs consistently outperform others?" and "What are the implications for institutional strategy development?" (Lynch $\&$ Baines, 2004). Most of the cases within research that consider the performance evaluation of HEIs come from Western countries (Colbert, Levary, \& Shaner, 2000; Korhonen, Tainio, \& Wallenius, 2001; Abbott \& Doucouliagos, 2003) while few studies have been conducted regarding Asian HEIs' performance, especially those in Taiwan. In particular, concerning public and private HEIs, Taiwan's public HEIs possess more educational resources and better reputations compared to private institutions; therefore they better meet students' needs and attract more public donations and institutional funds. For this reason, exploring the performance and development of HEIs in Taiwan is an interesting and meaningful research issue (Beard, 2009).

HEIs can be deemed well-structured organizations (Kale, 2013). Although consideration factors related to institutional development and institutional growth differ greatly among them (Chapple, Lockett, Siegel, \& Wright, 2005), some scholars have suggested that performance evaluations still should contain measurements of research, teaching, and service outcomes (Henry \& Neville, 2004; Nevilli \& Henry, 2006; Parks \& Riggs, 1993). By referring to discussions in the literature about organizational management, one can further understand the keys to success. From a systematic viewpoint, factors that influence organizational operations can be roughly divided as internal and external (Lee, Lee, \& Pennings, 2001). In terms of internal factors, scholars have focused on the quantity and attributes of internal resources using the resource-based view (RBV; Barney, 1991; Penrose, 1959; Wernerfelt, 1984). They have suggested that the development and performance of an organization depends on the quantity of resources it owns (Barney, 1991). Regarding external factors, relational resources bring HEIs several advantages that enable them to resolve competitive conflicts, obtain greater learning benefits, deal with turbulence and environment uncertainty, and absorb external resources (Feldman \& Schipper, 2007; Leana \& Pil, 2006; Walter, Auer, \& Ritter, 2006). Accordingly, assets gained from external relations and leverage effects are called social capital (Leana \& Van Buren, 1999; Nahapiet \& Ghoshal, 1998; Yli-Renko, Autio, \& Tontti, 2002).

This study builds on previous work by explicitly addressing from internal and external sources the underlying mechanisms that facilitate the improvement of HEIs' 
performance. Although the RBV and social capital theory have achieved remarkable results in studies in the field of education, little research has been conducted on resource variables specific to HEIs. Therefore, exploring the relationship between resource variables and institutional performance will give rise to practical implications regarding institutional governance and theoretical foundations of institutional research, as well as significant insights to HEIs in other countries facing similar situations.

The present study has three purposes. Firstly, it explores how HEIs utilize educational resources to realize and improve their performance by using the RBV to divide organizational resources into two categories: university reputation (Boyd, Bergh, \& Ketchen, 2010) and slack resources (Nohria \& Gulati, 1996; Su, Xie, \& Li, 2009; Voss, Sirdeshmukh, \& Voss, 2008). Secondly, it considers the internal and external social capital of HEIs to discuss whether or not this capital makes theoretical research sufficiently practical, standardizes service, and enriches education for students (Adler \& Kwon, 2002; Leana \& Phi, 2006). Thirdly, it examines the mediating role of institutional resources on social capital and performance, and it discusses the relations between these three aspects based on a literature review.

The remainder of this paper has been organized as follows. The research framework was developed first then the literature review and hypotheses were discussed. Afterwards, this study described the model and hypotheses testing by using data from professors in Taiwan. Finally, the research findings were discussed and theoretical and managerial implications explored, along with a discussion of the study's limitations and future research directions.

\section{Literature Review and Hypothesis Development}

\section{Resources of HEIs}

The RBV identifies "internal" organizational resources as circulating and tradable goods; it discusses resources from the perspectives of characteristics, accessibility, mode, process, and channel (Penrose, 1959; Ansoff, 1965). As the RBV has been widely used and developed in studies conducted on for-profit (Barney, 1991; Dai \& Kittilaksanawong, 2014; Voss et al., 2008) and non-profit organizations (Boyd et al., 2010; Kraatz \& Zajac, 2001), it can also help one understand the operation of HEIs for the following reasons.

Firstly, HEIs look for survival and development opportunities in a fierce competitive environment that often entails dramatic changes to the industrial structure (Washington \& Ventresca, 2004); however, the competition between HEIs for financial and human-capital resources mainly lies in raising research funds and recruiting suitable teachers and students (Boyd et al., 2010). Secondly, similar to enterprises, HEIs 
often suffer from resource shortages while maintaining huge institutional operating and academic research costs; thus, administrators must make additional efforts to maintain resources effectively and efficiently (Kraatz \& Zajac, 2001; Ryan, 2005). Furthermore, Ryan (2005) held that institutions should input reputation and resources including institutional support, budget, and financial resources. Thus, with respect to the aspects of resources that influence the development of HEIs, this study aims to evaluate the attributes of institutional slack resources (ISR) and reputation.

ISR. Size is always deemed a significant variable in strategic and organizational studies (George, 2005), which means that larger organizations possess higher legitimacy (Hannan \& Freeman, 1984), more abundant resources, and stronger bargaining power. These potential and available resources can be used to realize the organization's goals and ensure ideal organizational performance through transfer or reallocation (George, 2005). RBV scholars have suggested that slack resources can bring about more competitive advantages (Tan \& Peng, 2003) by narrowing internal boundaries, encouraging innovation (Nohria \& Gulati, 1996), and assisting administrators in responding to environmental changes more effectively (Cheng \& Kesner, 1997).

In the extensive education market, it is necessary to discuss the relationship between ISR and performance for the following reasons. Firstly, in the highly unstable and uncertain environment in which HEIs operate, they need to develop new operational policies and schemes in order to grasp new opportunities and maintain their competitive advantages (Li \& Atuahene-Gima, 2001; George, 2005); slack resources can support innovative service and school-related operations so as to enhance institutional performance (Nohria \& Gulati, 1996). Secondly, changes in strategic behavior are the primary factors for the survival and success of HEIs within this unstable environment (Kraatz \& Zajac, 2001); ISR can support current strategic behavior to adapt to environmental change dynamically so as to further enhance performance (Li \& Peng, 2008). Finally, due to the lack of educational resources on the market, HEIs cannot obtain enough of these (Khanna \& Palepu, 2000); slack resources may represent a valuable, unique, and specific source that could have great impact on institutional performance. Ryan (2005) discussed the relationship between financial resources, institutional expenditures, and student engagement; he showed that only instructional expenditures have a significant influence on teaching and service performance (Dai \& Kittilaksanawong, 2014). The first hypothesis of this study is:

H1: ISR is positively related to institutional performance (teaching, service, research).

Institutional reputation. The RBV regards reputation as a type of intangible asset that consists of internal investment and external evaluation (Dowling, 2001; Roberts \& Dowling, 2002). From this perspective, reputation can be defined as a series of 
general organizational characteristics (Roberts \& Dowling, 2002) that provide organizations with greater value-creation and performance advantage (Barney, 1991; Boyd et al., 2010). Reputation within HEIs involves the synthesis of organizational images and identifications generated by various stakeholders in specific situations (Flyvbjerg, 2006). Identifying the causes of reputation and other factors is important in order to explore why and how HEIs should convey certain organizational images and identifications (Siebert \& Matin, 2013); this is similar to brand reputation in marketing management (Chaudhuri, 2002). In this study, the concept of businessbrand reputation has been extended to HEIs because they also have their own brands.

Reputation is the cornerstone of an institution's strategy for differentiation. HEIs with higher reputations can have stricter entrance requirements (as a better choice), higher earnings (as a more attractive choice), and high-quality students with higher learning absorption (Lynch \& Baines, 2004; Monks \& Ehrenberg, 1999; Siebert \& Martin, 2013). This is because factors of academic and institutional reputation are related to resource intensity (Peters, 2007), which can lead to the Matthew effect where the rich get richer and the poor get poorer (Corley \& Gioia, 2000).

Institutional reputation is a broad term containing various factors that provide HEIs with greater legitimacy and validity (Rindova, Williamson, Petkova, \& Sever, 2005); it is a demonstration of quality closely related to HEIs' postgraduate courses, the research abilities of their faculties, institutional ranking, and affiliations with superior universities (Boyd et al., 2010). Scholars have verified the effect of reputation at the university (Volkwein \& Sweitzer, 2006) and college levels (Sweitzer \& Volkwein, 2009), and these results have shown that reputation is positively related to (1) student recruitment, (2) college entrance examination scores, and (3) research performance. Moreover, institutions with higher reputations can cooperate with external academic organizations as well as share research experience and academic information with each other (Bergh, Ketchen, Boyd, \& Bergh, 2010; Henry \& Neville, 2004). Thus, the second hypothesis of this study is:

H2: Institutional reputation is positively related to institutional performance (teaching, service, research).

\section{Social Capital}

The concept of social capital was first proposed by Bourdieu (1986, p. 248), who defined it as "the aggregate of actual potential resources linked to the possession of a durable network of more or less institutionalized relationships of mutual acquaintance or recognition." Nahapiet and Ghoshal (1998) also defined social capital as the current or potential embedded resources obtained by individuals or social units, or transferred from social relationships. Drawing on the arguments of Adler and 
Kwon (2002), Leana and Phi (2006), and other scholars, this study discusses the relationship between social capital and HEI performance, and verifies the results from an integrated viewpoint. Here, social capital can be considered as being divided into internal and external parts.

Internal social capital. Internal social capital can be described as the structural and relational content between individuals within the organization (Adler \& Kwon, 2002). Nahapiet and Ghoshal (1998) summarized previous studies to propose that social capital consists of structural, relational, and cognitive dimensions. First, the structural dimension presents all the patterns of ties between network members and explores whether they can obtain an advantageous position in the relationship network. Second, in the relational dimension, trust is the main factor in establishing a social network (Bryk \& Schneider, 2002; Kale, 2013; Leana \& Van Buren, 1999); organizations should believe that members have the ability and willingness to exchange or combine knowledge, and organizations should lower the risk inherent in knowledge exchange (Leana \& Phi, 2006). Third, the cognitive dimension involves the common expression, interpretation, and implications of social members; it can unify the behaviors of individuals (Leana \& Van Buren, 1999).

This study has placed HEIs in the context of its research because information sharing, extensive service, and effective teaching are all essential for studies on social capital (Leana \& Phi, 2006). Scholars have argued that more diversified and higher quality interactions between teachers are conducive to enhancing university performance (Bryk \& Schneider, 2002; McLaughlin \& Talbert, 2001). However, teaching in HEIs has always been seen as an indispensable human resource that requires bureaucratic control (Sarason, 1990) to combine the individual professional norms of teachers. These norms are broken gradually, as universities can be treated as professional communities whose responsibility is to generate, combine, and transfer professional knowledge throughout different fields (McLaughlin \& Talbert, 2001; Smylie \& Hart, 1999).

The internal relationship between HEIs can be regarded as a channel for developing and spreading effective teaching methods and maintaining common concerns wherein the ultimate goal is to enhance students' learning outcomes (Bryk \& Schneider, 2002; Smylie \& Hart, 1999). In order to realize this common goal, internal members of HEIs should enhance team-based professional development, inter-year teamwork, inter-departmental resource exchange, as well as the quantity and quality of academic and teaching knowledge that is obtained (Bryk \& Schneider, 2002; Leana \& Van Buren, 1999; McLaughlin \& Talbert, 2001; Smiley \& Hart, 1999). Therefore, the third hypothesis of this study is:

H3: The internal social capital of HEIs is positively related to institutional performance (teaching, service, research). 
External social capital. External social capital mainly relates to repeated connections such as resources, relationships, and information between a group of individuals, groups, or organizations (Adler \& Kwon, 2002; Calabrese, 2006; Laursen, Masciarelli, \& Prencipe, 2012). Laursen et al. (2012) discussed the influence of localized social capital on institutional knowledge creation and acquisition from the perspective of geographical proximity and social capital. This study has adopted their definition of social capital that uses social interaction and political participation as the measurement dimensions of localized social capital (Laursen et al., 2012). Social interaction can reflect the breadth of social relationships within HEIs, including informal organizations and associations, as well as their degree of socialization in these interactions (Putnam, 2000). Political participation refers to the relationship between organizations and stakeholders who influence the formulation and implementation of public policy or educational policy, whether directly or indirectly.

Compared with for-profit business units, HEIs should have deeper relationships with their external environment (Leana \& Pil, 2006) since HEIs are under intense public supervision and have to manage diversified external relationships (Calabrese, 2006). Institutional administrators, especially the presidents, play an important role in obtaining external resources and support from the local government for enhancing an HEI's sense of responsibility, for adjusting the constitution, and for improving institutional performance (Smylie \& Hart, 1999). Lou (2003) reported that when the factor of production mobility suffers from government intervention and limited access to resources, the relationship among HEIs, governmental units, and political parties becomes an important source of resources. This is because governmental units still control most strategic key resources and hold considerable power over project inspection and resource allocation ( $\mathrm{Li} \&$ Zhang, 2007). Hence, institutional administrators must also maintain close relationships and contact with political parties (Child, 1994). Improving the equipment available to HEIs and establishing an effective management system (Li \& Atuahene-Gima, 2002; Li \& Zhang, 2007) can enhance institutional performance. Therefore, external social capital can facilitate new resources and knowledge as well as enhance performance in teaching, service, and research. In light of this, the fourth hypothesis of this study is:

\section{H4: External social capital of HEI is positively related to institutional performance} (teaching, service, research).

In addition to improving their internal coordination ability, organizational members need to deal with all of the valuable information and knowledge that has been collected from their external environment (Zaheer \& Bell, 2005). Most previous studies have focused on how to apply knowledge and information collected from networked partners to improve the performance of competitive advantages (Adler \& Kwon, 2002; George, 2005). This study posits some ambiguities about the 
relationship between social capital and institutional performance. More significantly, scholars have found that social capital within HEIs is positively related to valuable information, resources, and knowledge; this in turn contributes to the creation of institutional value (Tsai \& Ghoshal, 1998).

Higher internal and external social capital are conducive to meeting the demand of HEIs for information collection and can mitigate the negative effect caused by a high imbalance or redundancy of internal resource reallocation (Gupta \& Govindarajan, 2000; Persson, 2006). In addition to enhancing the outcome of student learning and the external word-of-mouth effect (Bryk \& Schneider, 2002; Smylie \& Hart, 1999), valuable ISR should be accumulated to facilitate the improvement of institutional performance (Bryk \& Schneider, 2002; McLaughlin \& Talbert, 2001). Hence, the following hypothesis has been proposed. In addition, the research framework has been composed according to the research purposes and hypotheses, as shown in Figure 1.

H5: The relationship between social capital and institutional performance is mediated by institutional resources.

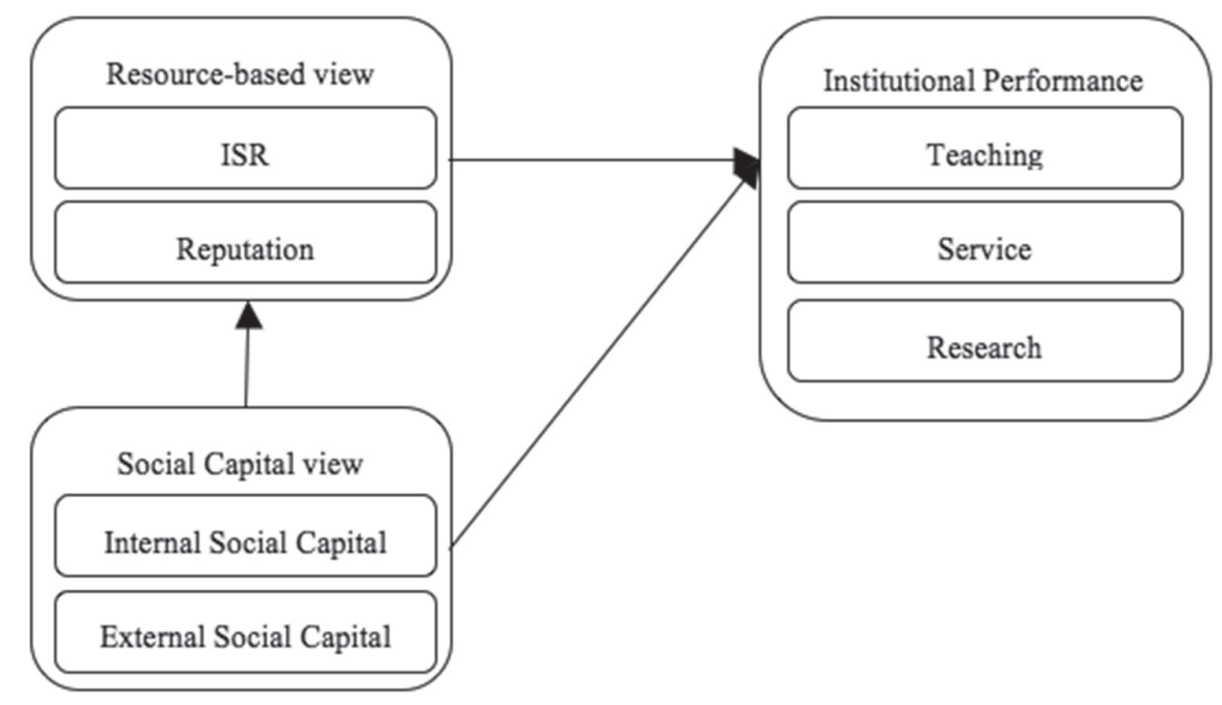

Figure 1. Conceptual framework.

\section{Methodology}

\section{Sample and Data Collection}

The research was conducted using Taiwanese HEIs. The survey employed a stratified random sampling method to collect data from 63,238 professors in 166 Taiwanese HEIs. While assembling the sample for the study, location (Northern, Central, Southern), classification (public and private universities; general and 
vocational universities), and size (large, medium, small) served as the criteria for university selection as these were assumed to be the defining features of HEIs in Taiwan. Accordingly, 30 HEIs in size ( 3 large, 9 medium and 18 small), location (10 institutions per region), and classification (15 institutions each), were randomly selected. In turn, $3.2 \%$ to $7.0 \%$ of the professors from each institution were randomly selected. The professors from these 30 HEIs were selected as key survey respondents who possessed institutional knowledge about formal and informal academic processes that are difficult to observe.

Before actual data collection, a pre-test was conducted on 40 professors randomly selected from 10 HEIs. The feedback received from these professors revealed that the survey instrument was appropriate with no need to modify any items on the scale. After excluding these 40 professors, the survey packages were sent by post to a total of 2,000 professors from the $30 \mathrm{HEIs}$ in 2014. Each survey package contained a cover letter explaining the survey purpose, a survey instrument, and a pre-paid envelope.

A total of 935 survey instruments were returned. Nine survey instruments were eliminated from the posted sample because of an excess in missing data and/or suspected careless responses; this yielded 926 valid survey instruments for an effective response rate of $46.3 \%$. According to the data gathered, 588 of the professors $(63.5 \%)$ were in universities in Northern Taiwan, 209 (22.6\%) were in Central Taiwan, and $129(13.9 \%)$ were in Southern Taiwan. There were 301 professors $(32.5 \%)$ from small universities, 443 (47.8\%) from medium ones, and 182 (19.7\%) from large ones.

\section{Measurement}

Institutional performance. Due to differences in the educational policy of each country, performance evaluations of HEIs also vary. In this study, we adopted measures from Belanger (1990), Marks and Printy (2003), Douglas and Sweitzer (2006), and the Ministry of Education in Taiwan (2014), and we assumed that HEI performance could be further assessed by examining teaching, research, and service outcomes. Teaching outcomes were composed of five items: teaching quality, instructional interaction, teaching creativity, teaching materials, and course setting and arrangement. Research outcomes were measured using four items: publication, patent and innovative productions, plans and study projects, and university-industry collaborations. Service outcomes were measured using five items: internal operational procedures and fundraising within the HEI, students' extra-curricular learning/ academic assistance; instructing students to participate in various competitions, social service, and public-benefit activities.

ISR. This refers to the stock of excess resources available to HEIs during a given planning cycle. Following Su et al. (2009) and Voss et al. (2008), this study holds that 
ISR is measured using financial, customer (student) relational, operational, and human resources; HEIs have been placed in the context of the research for the six-item ISR scale.

Reputation. Reputation refers to the extent of public awareness and popularity of the HEI. Reputation was measured using Chaudhuri's (2002) four-item scale and the "performance of graduates," because HEI reputation is accumulated over time as a joint effort by internal faculties and graduates. Brand reputation is closely related to graduates.

Internal social capital. Internal social capital in the context of HEIs focuses on how organizational members coordinate the structure, routines, and procedures of the institution, as well as how they communicate, interact, and cooperate effectively to facilitate organizational operations and lower operational costs. Based on the viewpoint of Nahapiet and Ghoshal (1998) regarding social capital, this study assumes internal social capital to consist of structural, relational, and cognitive dimensions which are in line with Yli-Renko et al. (2002) and Leana and Pil (2006). The structural, relational, and cognitive facets of social capital were operationalized as information-sharing, trust, and shared vision among faculties. They were measured using six items each.

External social capital. External social capital refers to HEIs' access to the valuable knowledge assets that can facilitate organizational performance through the establishment of external social relations. To measure the external social capital of HEIs in Taiwan, survey items were used based on Lauren et al.'s (2012) two variables (social interaction and political participation) and were measured using seven and three items, respectively.

\section{Result and Analysis}

\section{Reliability and Validity}

All scales used in this study were found to be reliable, with Cronbach's $\alpha$ ranging from 0.83 to 0.96 . Table 1 shows the reliability of each scale and the factor loadings for each item therein. In order to gauge validity, this study employed confirmatory factor analysis (CFA) using LISREL 8.54 to verify the scales' construct validity (both convergent and discriminant). The measurement model provided good fit to the data, $\chi^{2}(378)=1271.404$, Tucker-Lewis Index $(\mathrm{TLI})=.95$, Comparative Fit Index (CFI) $=.96$, Standardized Root Mean Square Residual $(\mathrm{SRMR})=.023$, Root Mean Square Error of Approximation (RMSEA) $=.051$. Hair, Black, Babin, Anderson, \& Tatham (2006) recommended convergent validity criteria as follows: (1) a standardized factor loading of higher than 0.7 , (2) average variance extracted (AVE) above 0.5, and (3) composite reliability (CR) above 0.7 . The evaluation standard for discriminant validity is the square root of AVE for one dimension greater than the correlation 
coefficient with any other dimension(s). As Table 1 indicates, all three criteria for convergent validity were met, and correlation coefficients were all less than the square root of the AVE within one dimension, suggesting that each dimension in this study had good discriminant validity.

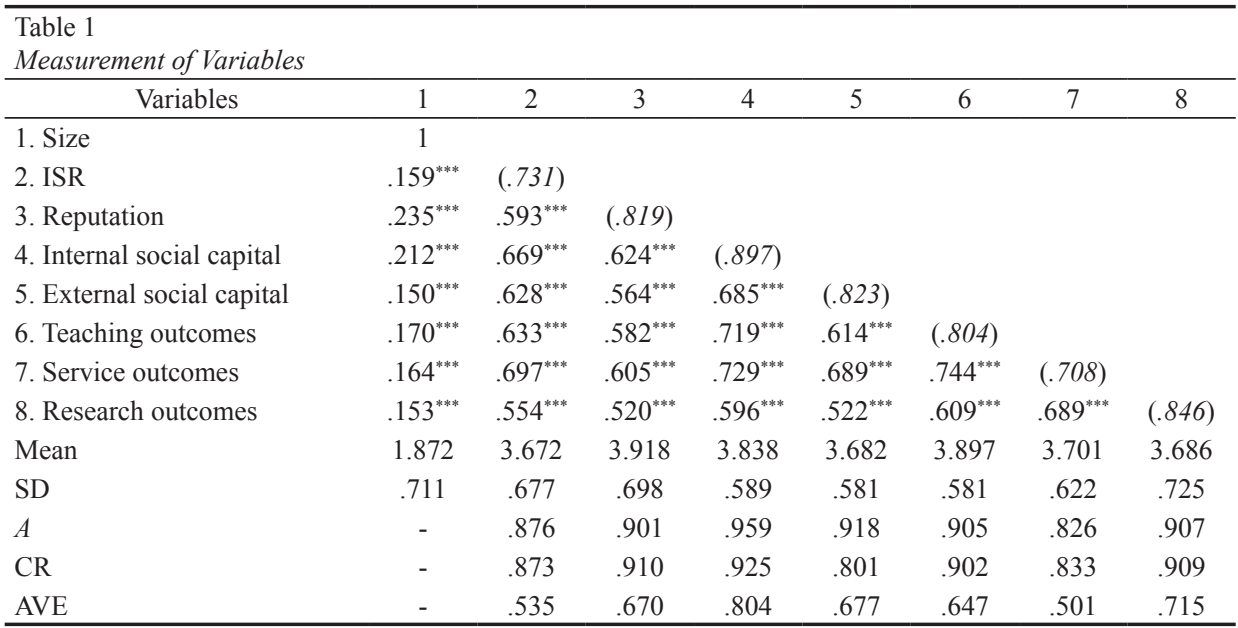

Notes. $* * * p<.001$. Diagonal (italic) elements are square roots of the AVE; note that AVE is not applicable for single-item measures.

\section{Main Effect Analysis of the Structural Model}

This study used SEM to estimate the model. In particular, when measurement error and correct paths for attenuation are taken into consideration, measurement unreliability is less of a problem (Grewal et al., 2004). The structural model provided good fit to the data, $\chi^{2}(378)=1210.878$, TLI $=.95$, CFI $=.96$, SRMR $=.026$, RMSEA $=.049$. In Figure 2, the main results of the model are summarized, including the corresponding standardized path coefficients. Path analysis attested that the standardized path coefficient of ISR for the teaching, $\beta=.208, p<.001$; service, $\beta=.297, p<.001$; and research outcomes, $\beta=.230, p<.001$, reached statistical significance, thus supporting H1. Similarly, the standardized path coefficient of reputation in teaching, $\beta=.077, p<.05$; service, $\beta=.088, p<.01$; and research outcomes, $\beta=.112, p<.01$, also attained statistical significance, thereby supporting H2. The standardized path coefficient of internal social capital for teaching, $\beta=.481$, $p<.001$; service, $\beta=.348, p<.001$; and research outcomes, $\beta=.322, p<.001$, reached statistical significance, which supports H3. Finally, external social capital had a significant effect on teaching, $\beta=.149, p<.01$; service, $\beta=.286, p<.001$; and research outcomes, $\beta=.126, p<.05$, thus supporting $\mathrm{H} 4$. 


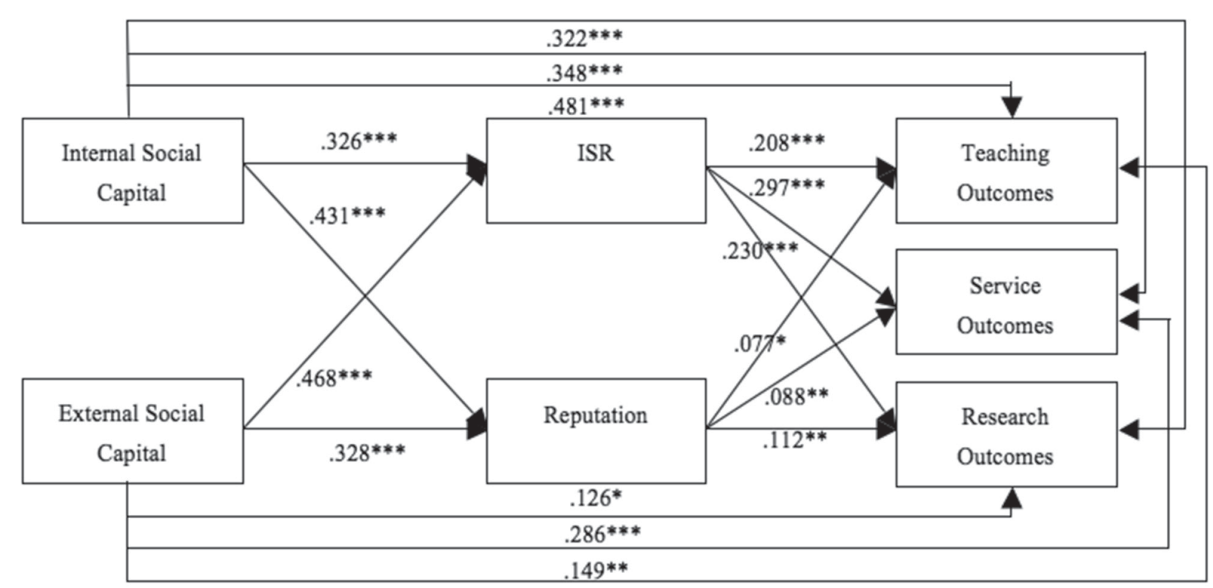

Figure 2. Structural equation modeling with standardized coefficients.

\section{Mediating Role of Institutional Resources}

While adopting the approach used by Baron and Kenny (1986), this study used SEM to test and verify the mediated model; these were required to meet the following four conditions. As can be seen from Condition (1) in Figure 3, the relationships between independent and mediated variables had positive significance; these results show that internal, $\beta=.335, p<.001 ; \beta=.471, p<.001$, and external social capitals, $\beta=.433, p<.001 ; \beta=.271, p<.001$, had significant positive effects on institutional slack and reputation. In Condition (2), the independent variables of internal and external social capital had significant positive effects on the dependent variables of teaching, $\beta=.601, p<.001 ; \beta=.242, p<.001$; service, $\beta=.573, p<.001 ; \beta=$ $.330, p<.001$; and research outcomes, $\beta=.455, p<.001 ; \beta=.250, p<.001$. In Condition (3), the relationships between the mediated variables (institutional slack and reputation) and dependent variables (teaching, service, and research outcomes) had positive significance. In Condition (4), which added the mediated variables of institutional slack and reputation, the results showed that the previous significant positive effects of internal and external social capital on teaching, service, and research outcomes became insignificant and negative. In summary of the individual variables, institutional slack and reputation satisfied the verification conditions provided by Baron and Kenny (1986) for the full mediating role between internal and external social capital with institutional performance (teaching, service, and research outcomes). Hypotheses $\mathrm{H} 3$ and $\mathrm{H} 4$, regarding the mediating effect of institutional resources on the relationship between social capital (both internal and external) and institutional performance, were thus fully supported. The relationship between social capital (internal and external) and institutional performance was mediated by institutional resources, supporting $\mathrm{H} 5$. 


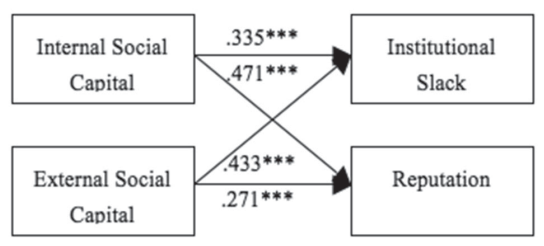

Condition (1)

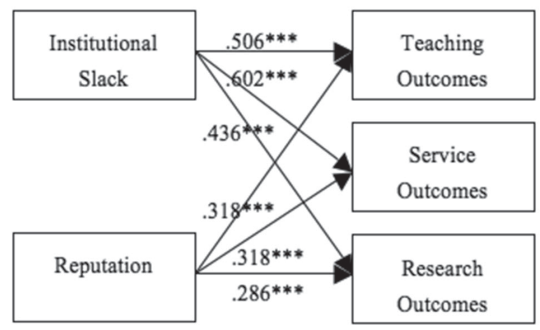

Condition (3)

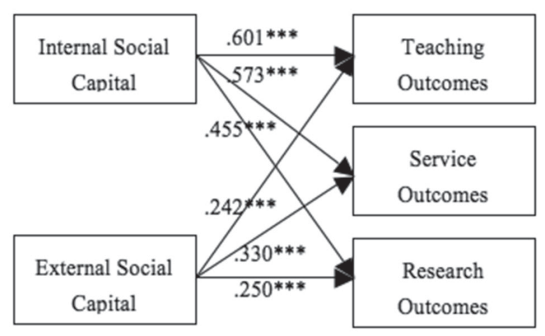

Condition (2)

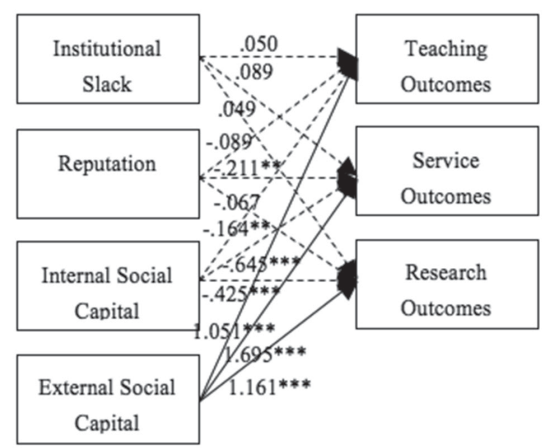

Condition (4)

Figure 3. Test of mediating effect.

\section{Multi-group Testing}

The size of HEIs was found to not merely represent the quantity of students, but also indirectly indicate the economic resources of the HEI (such as tuition), which exerts a positive effect on resource allocation and even influences HEI performance. Therefore, this study further explored the differences of variables in large, medium, and small HEIs. Model fit in these three sizes was acceptable, large, $\chi^{2}(383)=725.41$, $\mathrm{TLI}=.94, \mathrm{CFI}=.95$, SRMR $=.03$, RMSEA $=.06$; medium, $\chi^{2}(380)=1017.36$, $\mathrm{TLI}=.93, \mathrm{CFI}=.94, \mathrm{SRMR}=.03, \mathrm{RMSEA}=.06$; and small, $\chi^{2}(379)=599.95$; $\mathrm{TLI}=.93$; CFI $=.94, \mathrm{SRMR}=.03$; RMSEA $=.06$. Consequently, we examined relationship generalizability across the three sizes using a multi-group model in which the structural paths were constrained to being equal. Generalizability across sizes can be assumed if changes in the chi-square statistic between the unconstrained and the constrained models are not significant. In this case, the chi-square statistic was significant when the paths in the measurement model were unconstrained across sizes, $\Delta \chi^{2}(46)=121.13, p<.001$. Conversely, the change in chi-square statistic when the path coefficients were constrained as equal was significant, $\Delta \chi^{2}(78)=178.82, p$ $<.001$. Therefore, the path coefficients did not appear to be generalizable across the three sizes, and the use of unconstrained coefficients, as provided in Table 2, was appropriate for examining the results. 


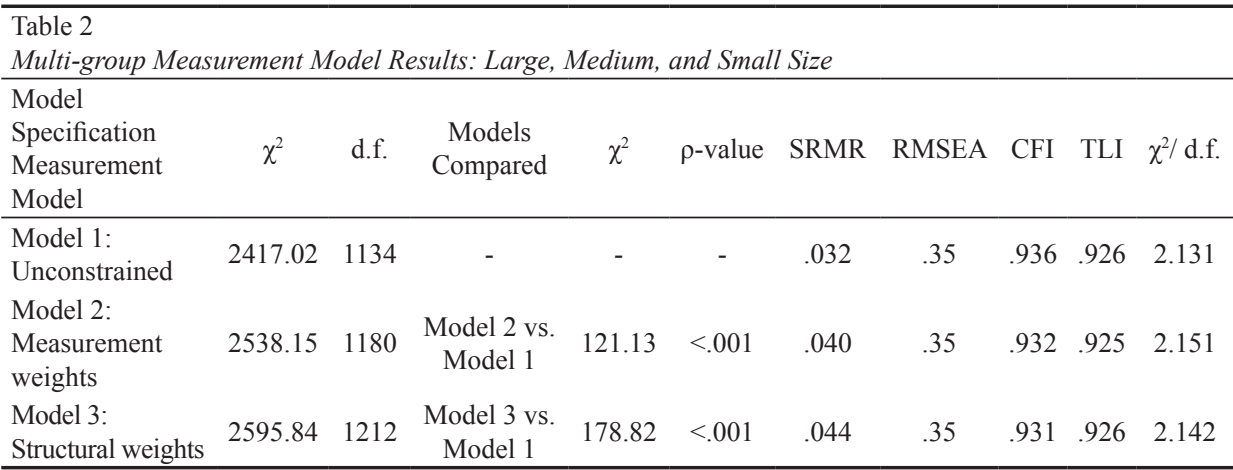

Hypothesis 1 showed that ISR is positively related to institutional performance (teaching, service, and research outcomes). In Table 3, this was the case in large, $\beta$ $=.267^{* * *}, .358^{* * *}, .207^{* * *}$, and medium-sized, $\beta=.194^{* * *}, 0.249^{* * *}, .303 * * *$, but not in small HEIs, $\beta=.035, .166^{*},-.051$. Hypothesis 2 proposed that higher reputation leads to enhanced performance. We found support for this hypothesis in the large, $\beta=.145^{* *}, .106^{*}, .278^{* * *}$, but not in the medium, $\beta=.042, .093^{* *},-.047$, or small HEIs, $\beta=-.015, .038, .120$. Hypothesis 3 indicated that HEIs with high levels of internal social capital have stronger performance. This relationship was in the expected direction and significant in all three sizes. Hypothesis 4 suggested that HEIs with higher external social capital would have better performance. This was the case in large, $\beta=.096, .286^{* *}, .192^{*}$, and medium, $\beta=.203^{* * *}, .331^{* * *}, 0.148$, but not small institutions, $\beta=.128, .180^{*}, .073$.

Table 3

Standardized Coefficients: Large, Medium, and Small Size

\begin{tabular}{lcccc}
\hline & Large & Medium & Small & Hypothesis \\
\hline ISR $\rightarrow$ Teaching outcomes & $.267^{* *}$ & $.194 * * *$ & .035 & \\
ISR $\rightarrow$ Service outcomes & $.358^{* * *}$ & $.249 * * *$ & $.166^{*}$ & H1: Partial support \\
ISR $\rightarrow$ Research outcomes & $.207^{* * *}$ & $.303^{* * *}$ & -.051 & \\
Reputation $\rightarrow$ Teaching outcomes & $.145^{* *}$ & .042 & -.015 & \\
Reputation $\rightarrow$ Service outcomes & $.106^{*}$ & $.093^{* *}$ & .038 & H2: Partial support \\
Reputation $\rightarrow$ Research outcomes & $.278^{* * *}$ & -.047 & .120 & \\
Internal social capital $\rightarrow$ Teaching outcomes & $.372^{* * *}$ & $.497^{* * *}$ & $.726^{* * *}$ & \\
Internal social capital $\rightarrow$ Service outcomes & $.280^{* * *}$ & $.360^{* * *}$ & $.567 * * *$ & H3: Partial support \\
Internal social capital $\rightarrow$ Research outcomes & .160 & $.314 * * *$ & $.616^{* * *}$ & \\
External social capital $\rightarrow$ Teaching outcomes & .096 & $.203^{* * *}$ & .128 & \\
External social capital $\rightarrow$ Service outcomes & $.286^{* *}$ & $.331^{* * *}$ & $.180^{*}$ & H4: Partial support \\
External social capital $\rightarrow$ Research outcomes & $.192^{*}$ & .148 & .073 & \\
\hline Notes. $p<.1, * * p .05, * * *<.01$ & & & &
\end{tabular}

Notes. $* p<.1, * * p<.05, * * * p<.01$. 


\section{Discussion and Conclusion}

This study demonstrated that influential factors affect HEI performance in Taiwan from the perspectives of social capital and RBV. Social capital and institutional resources play important roles and have been shown to improve institutional performance in organizational management literature; however, few studies have explored HEI performance development and improvement through organizational theories. Some scholars have also suggested a need to explain how to enhance HEI performance (Lynch \& Baines, 2004). Based on the results, these theoretical implications appear to contribute to institutional research in five ways. Firstly, this study took the different views of literature on social capital into account and proposed that the research should not focus on external social capital alone but should also consider internal social capital (Jansen, Van Den Bosch, \& Volberda, 2005). Secondly, the results supported the findings of earlier studies through a different setting (HEIs) and used data collected at the organizational level rather than that of a team or subunit. Thirdly, the performance implications of slack and reputation were identified: ISR was proposed to play a critical role in HEIs with respect to enhancing their teaching, service, and research outcomes, and to also be more important than reputation. This is consistent with the results of Tan and Peng (2003). Fourthly, we added a deeper and more finely grained understanding of how ISR and reputation mediate the relationship between social capital and performance. Finally, this study combined social capital and RBV into institutional research. The provision of new knowledge and insights about HEIs' required actions with respect to institutional governance is highly valuable.

Our results showed that internal and external social capitals are essential determinants of teaching, service, and research outcomes. The communications and interactions that the internal members of HEIs engage in to maintain mutual benefit and trust will enhance the internal working efficiency and learning effect of HEIs (Adler \& Kwon, 2002; Bryk \& Schneider, 2002); this will facilitate HEIs' understanding of students' learning needs so as to provide better teaching strategies and establish more attractive recruitment policies (Laursen et al., 2012; Leana \& Pil, 2006). Moreover, paths analysis reported that the influence of internal social capital on teaching, service, and research outcomes was higher compared to that of external social capital. Although HEIs' relative efforts at building external social capital appeared effective in terms of enhancing institutional performance (Calabrese, 2006), even though these effects were weaker than those for internal social capital, the acquisition of external resources was generally found to be unimportant. The fact that HEIs benefited most from internal social capital effects was further empirical confirmation that this contextual knowledge factor is a key advantage for higher performance (Leana \& Van Buren, 1999). 
Another major finding is that ISR, reputation, and institutional performance are significantly and positively related. With more ISR, which are likely to be valuable, unique, and hard to replicate, HEIs can support strategic behaviors to create a dynamic fit with the competitive educational environment and to further enhance their performance (George, 2005). Reputation also plays an important role in why some HEIs outperform others (Corley \& Gioia, 2000; Sweitzer \& Volkwein, 2009; Volkwein \& Sweitzer, 2006); this is an intangible resource that has financial consequences with respect to creating value. Furthermore, ISR had stronger positive influence on performance than reputation did. Both tangible and intangible assets are accumulated over time. Compared to reputation, ISR present higher mobility and elasticity; this can be reallocated during the course of HEIs' operation and have a significant influence on teaching, service and research outcomes.

As the results showed, ISR and reputation mediated the relationship between social capital and institutional performance. This suggests that instead of directly improving HEIs' performance, social capital may gradually increase performance through knowledge assimilation and the integration of certain characteristics and situations as mediators (George, 2005). Our results suggested that internal and external social capital could improve institutional performance through ISR and reputation. In order to consolidate ISR and reputation, HEIs should establish close relationships with external stakeholders while professors should practice mutual trust, unified norms, and common values so as to realize interaction and integration of resources through knowledge learning, thus facilitating improvements to institutional performance.

The results of the multi-group analysis revealed significant differences between the large, medium, and small institutions in the social capital-performance and institutional resources-performance relationships. This study confirmed that each HEI, as a function of its history and past success, had different ISR available, and that these resource combinations were relevant in explaining inter-HEI variation within each outcome. More specifically, with respect to differences in the institutional resources-performance relationship, ISR and reputation had a stronger positive impact on teaching, service, and research outcomes for large HEIs than for smaller ones. Although small HEIs performed more poorly in terms of accumulating ISR, reputation, and external social capital compared to large and medium HEIs, the relationship significance between internal social capital and performance held higher standardized coefficients compared to the other two sizes. In other words, our findings suggested that small HEIs' internal members were often involved in identifying existing beliefs, values, norms, and mutual trust, as well as reinforcing the existing interactions, communication channels, and information sharing. 


\section{Practical Implications}

The findings of this study have several useful implications for HEI presidents and administrators to enhance performance. Firstly, the positive relationship between institutional resources and performance suggests that Taiwanese HEIs should focus on accumulating ISR and maintaining a well-established reputation to avoid the impact of structural risks, changes to educational policy, and other negative factors so as to maintain the quality of their teaching, service, and research. For institutional administrators, priority should be given to optimizing the allocation of different ISR internally in order to enhance HEIs' performance and protect them from threats of failure.

Secondly, in terms of the nature of education, HEIs exhibit great homogeneity. In order to differentiate themselves from one another, HEIs must emphasize their prominence within the education market (Boyd et al., 2010; Corley \& Gioia, 2000). In general, although our study added empirical evidence that reputation provides benefits to performance, no direct effect was noted between reputation and performance in medium and small HEIs. We suggest that there is great potential value in regularly reminding the public about HEIs' accomplishments and characteristics, such as geographical location, hardware and software facilities, quality of teachers, employment status of graduates, and even to strive for the Quacquarelli Symonds World University Rankings or the Times Higher Education World University Rankings.

Thirdly, consistent with a social capital approach, this study found that internal and external social capitals had positive effects on institutional performance (Leana \& Pil, 2006). According to transaction cost theory, organizational members fear that other members may duplicate their core knowledge and weaken their power in the organization (Williamson, 1985). Such opportunism and self-interest caused by private interests will eventually lead to failure of the knowledge-sharing system. Our findings emphasize the importance of internal social capital, and hold that long-term interactions, mutual trust, and mutual benefit will increase the consistency of the cognition and values of internal members (Bryk \& Schneider, 2002; Tasai \& Choshal, 1998) so that they will hold similar beliefs and interpretations by using a common language during the process of knowledge sharing, which is conducive to lowering transaction cost (Jansen et al., 2005).

Finally, from our multi-group analysis we found that internal members of small HEIs did not have to communicate in complex hierarchical organizations; thus, the short communication and interaction distance in small HEIs have a stronger impact on institutional performance compared to that of large and medium-sized HEIs. Due to the great quantity of professors in large HEIs, members may have professional pride because of differences in their beliefs and competition for positions; this can lead to an unwillingness to share and cooperate with each other. Therefore, this study 
suggests that large and medium-sized HEIs should intensify the communication and coordination of internal members, create a cohesive atmosphere, and establish closer social connections so that institutions can accomplish better teaching, service, and research outcomes through managing, integrating, and transferring common knowledge and skills. Furthermore, small HEIs, in addition to maintaining their existing internal social capital, should invest parts of their resources to accumulate external social capital because only external relationships can bring newer and more valuable information and knowledge. For example, small HEIs could cooperate with non-profit organizations to hold public-benefit activities so as to establish a positive social image and enhance their reputation; this would attract more scholars to engage in academic cooperation, more firms to provide employment opportunities for students, and more university-industry collaborations.

\section{Limitations and Future Directions}

Although our findings are significant for both institutional and educational research, there are several limitations. Firstly, this study emphasized that relationships are a kind of dynamic resource with great mobility; however, the nature of dynamic resources will lead to different stages of relationship development that can even impact the accumulation of social capital. Therefore, this study only used crosssectional resources, and may not be generalizable to the viewpoints of dynamic relationship development. Thus, future studies could focus on the co-evolution of social capital development stages and institutional performance. Secondly, this study discussed the performance improvement mode of Taiwanese HEIs using social capital and the RBV, and it explored how HEIs should maintain their strengths and mitigate their weaknesses to pursue sustainable development. Internal and external social capital, ISR, and reputation were conceptualized as both firm- and industry-level factors; thus, research that examines their multi-theoretical and multi-level nature is needed. Potential interaction effects between social capital and resources also need to be examined. For example, if an HEI has strong internal social capital and complete slack, it is imperative to explore whether performance improvements will be accrued from these two factors together, or whether synergy between them can create a multiplicative effect. Thirdly, the results are context-specific for Taiwan and caution should be used when generalizing them to other countries. Fourthly, although a positive relationship was noted among social capital, institutional resources, and performance, there has been little research to date on how HEIs should use their social capital and institutional resources to provide and sustain superior quality of teaching, service, and research. Thus, this issue should be addressed in future studies. 


\section{References}

Abbott, M., \& Doucouliagos, C. (2003). The efficiency of Australian universities, a data envelopment analysis. Economics of Education Review, 22(1), 89-97.

Adler, P. S., \& Kwon, S. W. (2002). Social capital, Prospects for a new concept. Academy of Management Review, 27(1), 17-40.

Altbach, P. G., Reisberg, L., \& Rumbley, L. E. (2009). Trends in global higher education: Tracking an academic revolution. Boston, MA: Boston College Center for International Higher Education Chestnut Hill.

Ansoff, H. I. (1965). Corporate strategy, business policy for growth and expansion. New York: McGraw-Hill Book.

Barney, J. (1991). Firm resources and sustained competitive advantage. Journal of Management, 17(1), 99-120.

Barney, J. B., \& Hesterly, W. S. (2009). Strategic management and competitive advantage: concepts and cases (3rd ed.). NJ: Prentice Hall.

Baron, R. M., \& Kenny, D. A. (1986). The moderator-mediator variable distinction in social psychological research: Conceptual, strategic, and statistical considerations. Journal of Personality and Social Psychology, 51(6), 1173-1182.

Beard, D. F. (2009). Successful applications of the balanced scorecard in higher education. Journal of Education for Business 84(5), 275-282.

Bergh, D. D., Ketchen, D. J., Boyd. B. K., \& Bergh, J. (2010). New frontiers of the reputationperformance relationship: Insights from multiple theories. Journal of Management, 36(3), $620-632$.

Bourdieu, P. (1986). The forms of capital. In J. G. Richardson (Ed.), Handbook of theory and research for the sociology of education (pp. 241-258). New York, NY: Greenwood Press.

Boyd, B. K., Bergh, D. D., \& Ketchen, D. J. (2010). Reconsidering the reputation-performance relationship: A resource-based view. Journal of Management, 36(3), 588-609.

Bryk, A., \& Schneider, B. (2002). Trust in schools, A core resource for improvement. New York: Russell Sage Foundation.

Calabrese, R. L. (2006). Building social capital through the use of an appreciative inquiry theoretical perspective in a school and university partnership. International Journal of Educational Management, 20(3), 173-182.

Chapple, W., Lockett, A., Siegel, D., \& Wright, M. (2005). Assessing the relative performance of UK university technology transfer offices, parametric and non-parametric evidence. Research Policy, 34(3), 369-384.

Chaudhuri, A. (2002). How brand reputation affects the advertising-brand equity link. Journal of Advertising Research, 42(3), 33-43.

Cheng, J. L., \& Kesner, I. F. (1997). Organizational slack and response to environmental shifts, the impact of resource allocation patterns. Journal of Management, 23(1), 1-18.

Child, J. (1994). Management in China during the Age of Reform (Vol. 89). Cambridge University Press.

Colbert, A., Levary, R. R., \& Shaner, M. C. (2000). Determining the relative efficiency of MBA programs using DEA. European Journal of Operational Research, 125(3), 656-669.

Corley, K., \& Gioia, D. (2000). The rankings game: Managing business school reputation. Corporate Reputation Review, 3(4), 319-333.

Dai, W., \& Kittilaksanawong, W. (2014). How are different slack resources translated into firm growth? Evidence from China. International Business Research, 7(2), 1-12. 
Douglas, A., \& Douglas, J. (2006). Campus spies? Using mystery students to evaluate university performance. Educational Research, 48(1), 111-119.

Feldman, M. P., \& Schipper, H. (2007). Bringing science to life, an overview of countries outside of North America. The Journal of Technology Transfer, 32(4), 297-302.

Flyvbjerg, B. (2006). Five misunderstandings about case-study research. Qualitative inquiry, $12(2), 219-245$.

Fornell, C., \& Larcker, D. F. (1981). Evaluating structural equation models with unobservable variables and measurement error. Journal of Marketing Research, 18(1), 39-50.

George, G. (2005). Slack resources and the performance of privately held firms. Academy of Management Journal, 48(4), 661-676.

Gupta, A. K., \& Govindarajan, V. (2000). Knowledge flows within multinational corporations. Strategic Management Journal, 21(4), 473-496.

Hair, J. F., Black, W. C., Babin, B. J., Anderson, R. E., \& Tatham, R. L. (2006). Multivariate data analysis (Vol. 6). Upper Saddle River, NJ: Pearson Prentice Hall.

Hannan, M. T., \& Freeman, J. (1984). Structural inertia and organizational change. American Sociological Review, 49(2), 149-164.

Henry, D. B., \& Neville, T. M. (2004). Research, publication, and service patterns of Florida academic librarians. The Journal of Academic Librarianship, 30(6), 435-451.

Hoang, H., \& Antoncic, B. (2003). Network-based research in entrepreneurship, A critical review. Journal of Business Venturing, 18(2), 165-187.

Jansen, J. J., Van Den Bosch, F. A., \& Volberda, H. W. (2005). Managing potential and realized bsorptive capacity, how do organizational antecedents matter? Academy of Management Journal, 48(6), 999-1015.

Kale, M. (2013). Perceptions of college of education students in Turkey towards organizational justice, trust in administrators, and instructors. Higher Education, 66(5), 521-533.

Khanna, T., \& Palepu, K. (2000). Is group affiliation profitable in emerging markets? An analysis of diversified Indian business groups. The Journal of Finance, 55(2), 867-891.

Korhonen, P., Tainio, R., \& Wallenius, J. (2001). Value efficiency analysis of academic research. European Journal of Operational Research, 130(1), 121-132.

Kraatz, M. S., \& Zajac, E. J. (2001). How organizational resources affect strategic change and performance in turbulent environments, Theory and evidence. Organization Science, $12(5), 632-657$.

Laursen, K., Masciarelli, F., \& Prencipe, A. (2012). Regions matter, how localized social capital affects innovation and external knowledge acquisition. Organization Science, 23(1), 177-193.

Leana, C. R., \& Pil, F. K. (2006). Social capital and organizational performance, Evidence from urban public schools. Organization Science, 17(3), 353-366.

Leana, C. R., \& Van Buren, H. J. (1999). Organizational social capital and employment practices. Academy of Management Review, 24(3), 538-555.

Lee, C., Lee, K., \& Pennings, J. M. (2001). Internal capabilities, external networks, and performance, a study on technology-based ventures. Strategic Management Journal, 22(6-7), 615-640.

Li, H., \& Atuahene-Gima, K. (2001). Product innovation strategy and the performance of new technology ventures in China. Academy of management Journal, 44(6), 1123-1134.

Li, H., \& Zhang, Y. (2007). The role of managers' political networking and functional experience in new venture performance, evidence from China's transition economy. Strategic Management Journal, 28(8), 791-804. 
Li, Y., \& Peng, M. W. (2008). Developing theory from strategic management research in China. Asia Pacific Journal of Management, 25(3), 563-572.

Luo, Y. (2003). Industrial dynamics and managerial networking in an emerging market: The case of China. Strategic Management Journal, 24(13), 1315-1327.

Lynch, R., \& Baines, P., (2004). Strategy development in UK higher education, towards resource-based competitive advantages. Journal of Higher Education Policy and Management, 26(2), 171-187.

Marks, H. M., \& Printy, S. M. (2003). Principal leadership and school performance: An integration of transformational and instructional leadership. Educational Administration Quarterly, 39(3), 370-397.

McLaughlin, M. W., \& Talbert, J. E. (2001). Professional communities and the work of high school teaching. University of Chicago Press.

Ministry of Education in Taiwan. (2014). University act. Retrieved from http://www.edu.tw/

Ministry of Interior in Taiwan. (2014). Fertility rates of childbearing age women. Retrieved from http://www.moi.gov.tw/stat/index.aspx

Nahapiet, J., \& Ghoshal, S. (1998). Social capital, intellectual capital, and the organizational advantage. Academy of Management Review, 23(2), 242-266.

Neville, T. M., \& Henry, D. B. (2007). Support for Research and Service in Florida Academic Libraries. The Journal of Academic Librarianship, 33(1), 76-93.

Nohria, N., \& Gulati, R. (1996). Is slack good or bad for innovation? Academy of Management Journal, 39(5), 1245-1264.

Organisation for Economic Co-operation and Development. (2004). Quality and recognition in higher education, The cross-border challenge. Paris, France: Author.

Park, B., \& Riggs, R. (1993). Tenure and promotion, a study of practices by institutional type. The Journal of Academic Librarianship, 19(2), 72-77.

Penrose, E. (1959). The theory of the growth of the firm. New York, NY: John Wiley.

Persson, M. (2006). The impact of operational structure, lateral integrative mechanisms and control mechanisms on intra-MNE knowledge transfer. International Business Review, $15(5), 547-569$.

Peters, K. (2007). Business school rankings, content and context. Journal of Management Development, 26(1), 49-53.

Podsakoff, P. M., MacKenzie, S. B., Lee, J. Y., \& Podsakoff, N. P. (2003). Common method biases in behavioral research, a critical review of the literature and recommended remedies. Journal of Applied Psychology, 88(5), 879-903.

Putnam, R. D. (2000). Bowling alone: The collapse and revival of American community. New York: Simon and Schuster.

Rindova, V. P., Williamson, I. O., Petkova, A. P., \& Sever, J. M. (2005). Being good or being known: An empirical examination of the dimensions, antecedents, and consequences of organizational reputation. Academy of Management Journal, 48(6), 1033-1049.

Roberts, P. W., \& Dowling, G. R. (2002). Corporate reputation and sustained superior financial performance. Strategic Management Journal, 23(12), 1077-1093.

Ryan, J. F. (2005). Institutional expenditures and student engagement, a role for financial resources in enhancing student learning and development? Research in Higher Education, 46 (2), 235-249.

Sarason, S. B. (1990). The predictable failure of school reform. San Francisco, CA: Jossey-Bass. 
Siebert, S., \& Martin, G. (2013). Reputational challenges for business schools: A contextual perspective. Education + Training, 55(4/5), 429-444.

Smylie, M. A., \& Hart, A. W. (1999). School leadership for teacher learning and change: A human and social capital development perspective. Handbook of Research on Educational Administration, 2, 421-441.

Su, Z., Xie, E., \& Li, Y. (2009). Organizational slack and firm performance during institutional transitions. Asia Pacific Journal of Management, 26(1), 75-91.

Sweitzer, K., \& Volkwein, J. F. (2009). Prestige among graduate and professional schools: Comparing the US News' graduate school reputation ratings between disciplines. Research in Higher Education, 50(8), 812-836.

Tan, J., \& Peng, M. W. (2003). Organizational slack and firm performance during economic transitions: Two studies from an emerging economy. Strategic Management Journal, 24(13), 1249-1263.

Taylor, B. J., Webber, K., L., \& Jacobs, G. J. (2013). Institutional research in light of internationalization: Growth, and competition. New Directions for Institutional Research, $157,5-22$.

Volkwein, J. F., \& Sweitzer, K.V. (2006). Institutional prestige and reputation among research universities and liberal arts colleges. Research in Higher Education, 47(2), 129-148.

Voss, G. B., Sirdeshmukh, D., \& Voss, Z. G. (2008). The Effects of Slack Resources and Environmental threat on Product Exploration and Exploitation. Academy of Management Journal, 51(1), 147164.

Walter, A., Auer, M., \& Ritter, T. (2006). The impact of network capabilities and entrepreneurial orientation on university spin-off performance. Journal of Business Venturing, 21(4), 541-567.

Washington, M., \& Ventresca, M. J. (2004). How organizations change: The role of institutional support mechanisms in the incorporation of higher education visibility strategies, 18741995. Organization Science 15(1), 82-97.

Wernerfelt, B. (1984). A resource-based view of the firm. Strategic Management Journal, 5(2), 171-180.

Williamson, O. E. (1985). The economic institutions of capitalism. New York: Simon and Schuster.

Yli-Renko, H, Autio, E., \& Tontti, V. (2002). Social capital, knowledge, and the international growth of technology-based new firms. International Business Review, 11(3), 279-304.

Zaheer, A., \& Bell, G. G. (2005). Benefiting from network position, firm capabilities, structural holes, and performance. Strategic Management Journal, 26(9), 809-825. 